\title{
A relação Estado e Educação: uma análise da produção acadêmica brasileira (1971-2000)
}

Nadia Gaiofatto Gonçalves (UFPR)*

Palavras-chave: Estado; educação básica; políticas educacionais: produção acadêmica; contexto histórico.
* Esta pesquisa foi realizada durante meu doutorado na Faculdade de Educação da Universidade de São Paulo (Feusp). Agradeço à Prof ${ }^{\mathrm{a}} \mathrm{Dr}^{\mathrm{a}}$ Sandra M. Zákia Lian Sousa, que a orientou, aos professores Elba S. Sá Barto pressores Pedro Jacobi, Sofia L. Vieira, Antônio J. Severino, Romualdo P. de Oliveira e José M. Pires Azanha (in memoriam), pelas contribuições, e à Fundação de Amparoà Pesquisa do Estado de São Paulo (Fapesp), que a financiou parcialmente. Contatos: nadia_ggoncalves@ufpr.br.

1 Ressalte-se que, nesta pesquisa, a produção acadêmica analisada voltou-se a publicações produzidas, em sua maior parte, po acadêmicos vinculados a Universidades e Associações Nacionais das áreas em questão. Não abrangeu, portanto, outros tipos de produção, como os advindos de Organizações Não-Governamentais ou Comissões internas ou Órgãos do Estado, a não ser quando estivessem nas publicações investigadas.

\section{Resumo}

Apresenta resultados de pesquisa realizada sobre se e como o tema Estado e Educação foi abordado na produção acadêmica brasileira no período compreendido entre 1971 e 2000. Foram pesquisados cinco anais de Associações Nacionais de Pós-Graduação e Pesquisa e 15 revistas das áreas de Economia, Administração, História, Ciências Sociais e Educação, sendo quatro títulos de cada uma delas na totalidade da produção do período. Buscou-se compreender as perspectivas das áreas (críticas, expectativas, entendimentos sobre a função do Estado em relação à Educação), considerando-se o contexto histórico das décadas em que os trabalhos foram produzidos e evidenciando seus nexos, contribuições e limitações.

\section{Introdução}

Nesta pesquisa visou-se desenvolver uma análise sobre se e como o tema Estado e Educação - referente à educação básica - foi abordado no período compreendido entre 1971 e 2000, em anais e revistas acadêmicas das áreas de Educação, História, Administração, Economia e Ciências Sociais.

O tema abordado remete às relações entre o Estado e a Educação no Brasil, mais especificamente ao seu papel e atuação em relação às políticas educacionais referentes à educação básica e à sua aplicação e efetividade. Buscou-se averiguar a forma como essa relação foi percebida, compreendida e analisada na produção acadêmica do País. A expectativa inicial era de que, nesse tipo de discurso, as relações entre as políticas educacionais, a atuação do Estado e o contexto mais amplo que os envolve seriam discutidos e evidenciados.
Tem-se o entendimento de que é dos programas de pós-graduação e das universidades que derivam, em sua grande maioria, os artigos publicados em periódicos acadêmicos e os trabalhos apresentados em eventos de repercussão nacional. Essa produção, ${ }^{1}$ quando voltada ao tema, pode ser útil para a compreensão da função estatal na área educacional, com suas críticas, análises, expectativas e proposições.

Nas Ciências Humanas, as áreas de História, Ciências Sociais, Administração e Economia foram as escolhidas para a investigação, devido à sua provável proximidade ou possível interdisciplinaridade com o tema enfocado. A opção por tratar da produção não somente da Educação deveu-se também à expectativa de serem identificadas outras visões a partir das preocupações e prioridades de cada área.

Assim, averiguaram-se as relações entre Estado e Educação em artigos e trabalhos sobre o tema, publicados nas diferentes áreas. 
As percepções dos autores foram analisadas como base para estabelecer as discussões e tratamentos dados ao tema no decorrer do período.

A fim de apreender as percepções presentes na produção acadêmica, foi estabelecido o período de 1971 a 2000. Esta delimitação temporal pretendeu abranger as Leis no 5.692/71 e no 9.394/96, fundamentais para a compreensão da educação básica no período abordado. A extensão até o ano de 2000, integrando três décadas completas na pesquisa, ocorreu visando-se captar as discussões a respeito do papel do Estado e seus reflexos na Educação no decorrer de um período histórico de grandes mudanças políticas, econômicas e sociais do País, como o fim da ditadura militar, a transição política e os questionamentos sobre o papel do Estado.

Abordar a totalidade desta década na pesquisa pareceu relevante, tendo em vista a reconfiguração do papel do Estado na gestão da educação pública, em âmbito internacional e nacional, suscitando estudos, pesquisas e produções acadêmicas. Pretendeu-se abranger as repercussões e discussões desenvolvidas na produção acadêmica a respeito da Lei de Diretrizes e Bases da Educação Nacional (LDB) de 1996, após sua promulgação, a partir do entendimento de que esta lei, mais do que decorrência do processo de reforma do Estado, faz parte dele.

\section{Referenciais analíticos}

Neste trabalho, o principal referencial analítico foi a teoria dos campos, de Pierre Bourdieu, complementada com as perspectivas de Roger Chartier, Peter Burke e Fernand Braudel.

Baseou-se nos conceitos de espaço social, campo, habitus, capital e poder simbólico, de Pierre Bourdieu, que enfatiza as limitações de entendimento de uma dada realidade e os determinantes histórico-sociais que a envolvem e que pesam sobre a produção do conhecimento a ela pertinente, embora considere que esta limitação configura, mas não determina a ação, sendo, porém, suficiente para criar padrões de comportamento e de interpretação.

A fim de melhor explicitar as relações entre os conceitos mencionados, Bourdieu (1988, p. 82-83) compara o funcionamento do campo à organização e ao desenvolvimento de um determinado jogo, cujas regras não são explícitas, mas são compreensíveis para os agentes que dele participam, a partir da noção de habitus:

[...] não se deve colocar o problema em termos de espontaneidade e coação, liberdade e necessidade, indivíduo e social. O habitus como sentido do jogo é jogo social incorporado, transformado em natureza. Nada é simultaneamente mais livre e mais coagido do que a ação do bom jogador. [...] O habitus como social inscrito no corpo, no indivíduo biológico, permite produzir a infinidade de atos de jogo que estão inscritos no jogo em estado de possibilidades e de exigências objetivas; as coações e as exigências do jogo, ainda que não estejam reunidas num código de regras, impõemse àqueles que, por terem o sentido do jogo, isto é, o senso da necessidade imanente do jogo, estão preparados para percebê-las e realizá-las. [...] E as regularidades que se podem observar, graças à estatística, são o produto agregado de ações individuais orientadas pelas mesmas coações objetivas (as necessidades inscritas na estrutura do jogo ou parcialmente objetivadas em regras) ou incorporadas (o sentido do jogo, ele próprio distribuído de modo desigual, porque em toda parte, em todos os grupos, existem graus de excelência).

Para Bourdieu, pode-se falar de regras, desde que se distinga regra de regularidade, pois se no jogo social as coisas se passam de forma regular, isso não quer dizer que seja uma regra, mesmo que uma atitude diferente da esperada seja considerada falta.

Pensar o tema Estado e Educação por meio de produção acadêmica de diferentes áreas implica necessariamente analisar as formas de percepção do tema a partir de seus enfoques. Os conceitos de habitus e de campo auxiliaram no entendimento das perspectivas das áreas acadêmicas selecionadas, uma vez que se esperava identificar em cada uma delas consensos internos, além de antagonismos.

Tratando-se da compreensão destes olhares, Chartier (1988) aborda a questão das leituras ou dos entendimentos possíveis, a partir da noção de representação, ou as diferentes formas que uma realidade é dada a ler - bastante próxima da noção de habitus. Segundo ele, as percepções dos sujeitos sociais não são neutras, dependendo do contexto em que foram elaboradas, e derivando delas as suas práticas. 
Mais especificamente se referindo às áreas acadêmicas, Braudel (1978) considera que "as ciências humanas se interessam todas por uma mesma e única paisagem: a das ações passadas, presentes e futuras do homem", sendo que representam observatórios, com suas "vistas particulares, seus esboços perspectivos diferentes" (p. 80). Ele ainda afirma que "as relações que podem existir entre as vistas que cada ciência lhe [ao observador] oferece, entre as explicações com as quais o pressionam, ou as teorias [...] que se lhe impõem", considerando que "a realidade no estado bruto não é senão uma massa de observações a organizar" (p. 81).

Por sua vez, e em concordância, Burke (1992, p. 15) destaca como "só percebemos o mundo através de uma estrutura de convenções, esquemas e estereótipos, um entrelaçamento que varia de uma cultura para outra". Ampliando esta idéia, cada ciência possui, também, esta sua percepção particular do mundo.

Os autores acima apresentados têm em comum o pressuposto de que uma dada realidade é passível de diferentes leituras. No caso desta pesquisa, isto se referiu às áreas acadêmicas selecionadas e seus entendimentos a respeito das relações entre Estado e Educação. Entendeu-se que estas diferentes perspectivas poderiam reportar-se às posições distintas que cada área ocupa no campo acadêmico, e pressupôs-se que, apesar disso, deveria haver consensos, estabelecidos, em grande parte, pelo contexto histórico.

Em certo sentido, a busca desse(s) consenso(s) está fundamentada em Bourdieu e em alguns conceitos próximos aos dele, de Thomas Khun. Este é o caso do campo científico, uma vez que ele conceitua uma comunidade científica em função dos paradigmas partilhados por seus elementos, mais fortes que seus eventuais desacordos.

A noção de habitus e a idéia da inculcação cultural também permitem uma aproximação, na medida em que, segundo Veiga Neto (1992, p. 102),

[...] a educação científica, para Kuhn, é uma atividade altamente conformadora dentro de um paradigma que é inculcado principalmente pelo uso do livro-texto ou manual (sempre paradigmáticos) e pelas práticas escolares que privilegiam uma determinada maneira de ver o mundo.
Ainda, ambos destacam a existência de períodos de transformação nas formas de entendimento, o que é designado como períodos de crise paradigmática por Kuhn e como rupturas epistemológicas por Bourdieu.

Esta perspectiva é interessante para a problemática desta pesquisa, uma vez que, no período de três décadas, foi possível identificar se houve ou não e, se houve, em que direção ocorreram as mudanças na forma de entendimento das relações entre Estado e educação básica no Brasil. Considera-se que os anais e revistas, ao mesmo tempo em que são instrumentos aglutinadores e difusores de análises e de conhecimento produzido, reforçam a legitimação de determinados enfoques e são influenciados por outros espaços institucionais e pelo contexto sócio-político-econômico, inclusive pela ação do Estado.

Dessa forma, as mudanças nos padrões de regulação do Estado, em desenvolvimento no período analisado, teriam agido como condicionantes para os rumos da produção acadêmica, embora pudesse haver alguma distância temporal entre essas alterações, a ação do Estado e a realização de estudos sobre elas. Buscou-se, então, identificar este movimento historicizando o debate acadêmico.

\section{Procedimentos metodológicos}

Foram investigadas 20 publicações, entre revistas e anais de Associações Nacionais das áreas citadas, na totalidade de suas produções em um período de três décadas.

Cinco dessas publicações eram os anais dos Encontros de Associações Nacionais das áreas respectivas: Anped (Educação), Anpuh (História), Anpad (Administração), Anpec (Economia) e Anpocs (Ciências Sociais). Esse tipo de publicação ofereceu dificuldades de localização, tanto em bibliotecas quanto nas secretarias das Associações, que, em sua maioria, não dispõem, em seus acervos, dos registros e materiais completos dos eventos que realizaram, tendo sido localizados parcialmente.

Por outro lado, as 15 revistas selecionadas foram localizadas na totalidade de suas publicações do período, conforme o Quadro 1. 


\section{Quadro 1 - Periódicos e períodos de publicação pesquisados}

\begin{tabular}{|l|l|}
\multicolumn{1}{|c|}{ Periódico - sigla utilizada } & \multicolumn{1}{c|}{ No/Período de publicação } \\
\hline Cadernos de Pesquisa (FCC) - CP & $n^{\circ} 1 / 1971-n^{\circ} 111 / 2000$ \\
\hline Educação e Sociedade (Unicamp) - EdS & $n^{\circ} 1 / 1978-n^{\circ} 73 / 2000$ \\
\hline Revista Brasileira de Educação (Anped) - RBEd & $n^{\circ} 1 / 1995-n^{\circ} 18 / 2000$ \\
\hline Estudos Históricos (FGV - CPDOC) - EH & $n^{\circ} 1 / 1988-n^{\circ} 26 / 2000$ \\
\hline Revista de História (USP) - RH & $n^{\circ} 85 / 1971-n^{\circ} 143 / 2000$ \\
\hline Revista Brasileira de História (Anpuh) - Anpuh & $n^{\circ} 1 / 1981-n^{\circ} 39 / 2000$ \\
\hline Revista de Administração Pública (FGV-RJ) - RAP & $n^{\circ} 5(1) / 1971-n^{\circ} 34(4) / 2000$ \\
\hline Revista de Administração (USP) - RAd & $n^{\circ} 6(1) / 1971-n^{\circ} 35(3) / 2000$ \\
\hline Revista de Administração de Empresas (FGV-SP) - RAE & $n^{\circ} 11(1) / 1971-n^{\circ} 40(2) / 2000$ \\
\hline Revista de Economia Política (CEP-RJ) - REP & $n^{\circ} 1(1) / 1981-n^{\circ} 20(2) / 2000$ \\
\hline Economia e Sociedade (Unicamp) - ESoc & $n^{\circ} 1 / 1992-n^{\circ} 15 / 2000$ \\
\hline Pesquisa e Planejamento Econômico (Ipea) - PPEc & $n^{\circ} 1 / 1971-n^{\circ} 30(2) / 2000$ \\
\hline Novos Estudos Cebrap - NECeb & $n^{\circ} 1 / 1971-n^{\circ} 57 / 2000$ \\
\hline Sociedade e Estado (UnB) - SEst & $n^{\circ} 1 / 1985-n^{\circ} 15(2) / 2000$ \\
\hline Revista Brasileira de Ciências Sociais (Anpocs) - RBCS & $n^{\circ} 1 / 1986-n^{\circ} 44 / 2000$ \\
\hline
\end{tabular}

No caso dos anais, quando os trabalhos foram identificados por resumos ou títulos nos programas dos eventos, realizouse uma tentativa de contato com os autores, por telefone (buscando-se informações nas instituições de vinculação, listas telefônicas e Internet) e/ou por e-mail, solicitandolhes o envio do texto integral ou a referência bibliográfica, caso o trabalho tivesse sido publicado após o evento.

A opção por incluir na pesquisa somente os trabalhos dos quais fossem obtidos os textos integrais visou evitar as limitações e dificuldades que a análise baseada somente em resumos ou catálogos pode trazer, quanto às informações apresentadas e à sua heterogeneidade e multifacetação, evidenciadas por Ferreira (2002, p. 267):

[...] as opções desses pesquisadores nos levam a questionar a natureza do material com o qual temos trabalhado: os resumos. É possível afirmar o que se tem falado sobre determinado tema ou área de conhecimento, em nosso país, num certo período, a partir só da leitura dos resumos? Um resumo poderia ser lido como parte de um todo? Que relação poderia ser feita entre cada resumo e o trabalho que lhe deu origem? É possível um olhar metonímico para cada resumo?
Se a opção adotada restringiu o número total de trabalhos selecionados, por outro lado permitiu que se seguisse padrão que garantiu a possibilidade de comparação da produção selecionada.

Foram utilizados, além do critério de texto integral, os seguintes parâmetros para a pré-seleção dos artigos: exaustividade e não-seletividade, pertinência ao tema e homogeneidade. Esses critérios, aplicados a partir de uma breve leitura dos artigos sobre o tema, nas publicações pesquisadas, levaram a uma pré-seleção de 286 trabalhos.

Em um segundo momento, numa nova leitura $^{2}$ a que foram submetidos os artigos pré-selecionados, utilizaram-se outros critérios para a seleção daqueles que constituiriam o material definitivo da pesquisa, contemplando o conteúdo e a autoria.

Os critérios estabelecidos quanto ao conteúdo foram: referência direta à relação Estado-Educação, ou seja, que tratasse do papel do Estado em relação às políticas educacionais, bem como às vicissitudes que têm caracterizado a concretização destas; e enfoque ou análise da educação básica (total ou parcialmente) no Brasil. Quando o artigo tratava da América Latina, somente seria incluído se apresentasse parte específica sobre o Brasil e tivesse delimitação temporal a partir da

\footnotetext{
2 Esta leitura mais aprofundada, que permitiu a seleção definitiva dos artigos, também serviu para a elaboração dos resumos da produção acadêmica que se enquadrava nos critérios estipulados na pesquisa.
} 
segunda metade do século 20 - assim, foram excluídos todos aqueles que discutiam o tema em períodos anteriores da educação no País.

Quanto à autoria, foram selecionados trabalhos produzidos por pesquisadores brasileiros ou por pesquisadores de origem estrangeira que mantinham vínculo institucional com Universidade ou Centro de Estudo brasileiros quando da sua publicação.

A partir dos critérios já explicitados, foram selecionados 202 artigos, posteriormente lidos, resumidos e classificados sob diversos quesitos, apresentados a seguir.

Ressalte-se que toda classificação implica uma leitura e análise dos textos. Assim, procurou-se elaborar e desenvolver essa fase visando identificar como a relação Estado e Educação foi entendida na produção acadêmica selecionada. Em especial aqueles itens concernentes aos temas, subtemas, referências ao Estado e expectativas, que são os mais subjetivos, não foram previamente estabelecidos, ou seja, surgiram no decorrer da leitura e análise do material.

A classificação dos artigos foi feita a partir dos elementos apresentados a seguir.

- Resumos: foram elaborados procurando-se evidenciar as ênfases dos autores quanto ao tema analisado e evitando-se copiar o resumo, já pronto, dos artigos.

- Revista: periódico ou anais em que foi apresentado o trabalho.

- Área: área de publicação do trabalho.

- Ano: o ano de publicação do trabalho.

- Instituição: instituição à qual o(s) autor(es) está(ão) vinculado(s).

- Natureza do texto: o corpus foi classificado em dois tipos - ensaio e pesquisa. Pesquisa foi subdividida em: histórica e descritivo-explicativa.

- Segmento educacional: segmento tratado nos artigos. Abrange: 1) educação escolar; e 2) outros âmbitos que não o escolar. A educação escolar divide-se em educação básica (aqueles que não faziam especificação de modalidade), educação infantil, ensino fundamental e ensino médio.

- Tema: os artigos foram classificados em sete temas, identificados a partir de suas recorrências no corpus da pesquisa, todos, obviamente, tratando da relação Estado e Educação, divididos, por sua vez, em subtemas, conforme as diferentes ênfases presentes nos textos.

- Referências ao Estado: nesse tópico, procurou-se identificar e evidenciar de que forma os autores trataram e analisaram o papel, as funções, a atuação, a presença ou, ainda, o modelo de Estado, em relação ao tema que discutiam, mais especificamente a Educação.

- Expectativas, sugestões e indicações: constituem as demandas dos autores, presentes nos trabalhos analisados, em relação à Educação e à atuação do Estado neste campo.

O resultado detalhado deste trabalho de classificação constitui o banco de dados da pesquisa, que contém as referências, os resumos e classificações dos 202 textos selecionados. A extensão desse material levou à opção de apresentá-lo em CD-ROM, disponibilizado juntamente com a tese (Gonçalves, 2003).

\section{A relação Estado e Educação no Brasil recente}

No contexto de questionamento, crise e reforma do Estado, presente e gradualmente acirrado nas últimas três décadas, a questão do Bem-Estar Social é um dos principais alvos de discussão. Especificamente no que se refere ao Brasil, deve-se considerar as deficiências desse setor e também as profundas desigualdades sociais; problemas estruturais e históricos, quanto aos aspectos político, econômico e cultural; e as novas exigências que as transformações mundiais trazem ao País e à Educação.

Além das perspectivas que discutem o Estado e seu papel nos aspectos econômico e político, há aquelas que analisam o tema abordando a forma como essas mudanças têm sido inseridas no contexto do País, em seu sistema de proteção social e suas conseqüências.

Draibe (1995, p. 202), analisando a política social brasileira, ressalta como

[...] seu desempenho foi medíocre e esteve sempre aquém das necessidades sociais da população, mesmo no período de sua expansão acelerada, aí entre meados dos anos 70 e 80 . Seus programas, mesmo os mais universais, pouco contribuíram para a redução das acentuadas desigualdades 
que marcam a sociedade brasileira; tiveram efeitos parcos ou quase nulos em suprimir os bolsões de pobreza; abrigaram e reforçaram privilégios; pautaram-se por uma grave dissociação entre os processos de expansão quantitativa e a melhoria da qualidade dos bens e serviços prestados. Os quase cinqüenta anos de construção do sistema de políticas sociais, no Brasil, se, a longo prazo, afetaram positivamente as condições da população mais carente, tiveram porém muito pouco sucesso em efetivamente estabelecer em patamar digno e de "bem-estar" o nível de vida dos brasileiros.

A Educação, enquanto atribuição estatal perante a sociedade, está inserida no debate sobre o papel e funções do Estado, o que vem sendo discutido juntamente com os problemas crônicos que a questão educacional envolve, como a formação dos professores, infra-estrutura física e humana da escola, acesso, permanência, currículo, qualidade e avaliação. Dessa forma, ela é parte constituinte do questionamento que Draibe (1995) faz às políticas públicas do País.

Lamounier (1997, p. 41) identifica uma recente ascensão da educação básica ao topo das prioridades da discussão, sobretudo em três sentidos: "como requisito mínimo de decência social, [...] como condição indispensável ao desenvolvimento econômico [...] e mais importante, (como) condição sine qua non para a redução das desigualdades sociais".
Porém, se há um certo consenso quanto a essa ascensão, não ocorre o mesmo quanto às formas como ela é entendida e trabalhada. Em especial na área educacional, algumas das principais críticas giram em torno da forma economicista com que os problemas da Educação vêm sendo tratados e as diretrizes estabelecidas.

Diante desses questionamentos, a produção acadêmica se destaca como fonte de reflexão sobre tais questões, além de expor preocupações e controvérsias acerca das relações entre Estado e Educação. Daí advém uma das contribuições desta pesquisa, como poderá ser observado no tópico seguinte.

\section{Principais resultados}

Considerando-se a limitação de espaço, serão apresentados neste tópico alguns dos principais resultados da pesquisa.

\section{A produção nas áreas}

A distribuição percentual dos 202 artigos, por área, está apresentada no Gráfico 1. Nele, fica evidenciada a grande concentração da produção na área de Educação, correspondente a 158 trabalhos. Nas demais áreas, a distribuição da produção foi a seguinte: Ciências Sociais - 21; Administração - 15; Economia - 5; e História - 3.

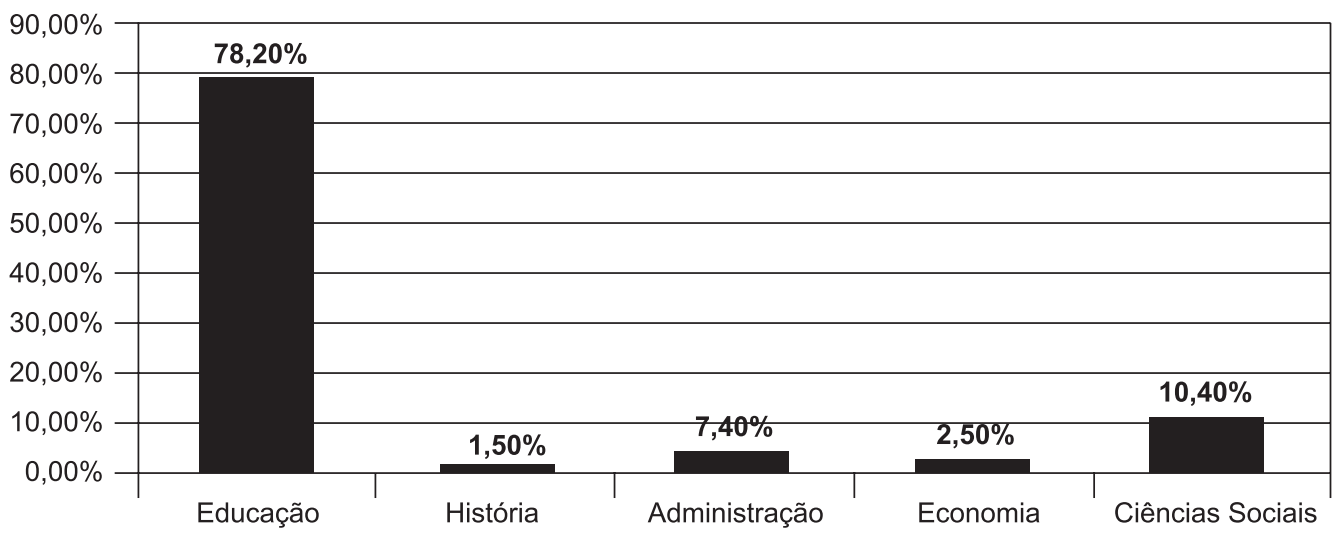

Gráfico 1 - Distribuição dos artigos por área (202)

Essa distribuição dos artigos foi bastante surpreendente. Embora se esperasse predominância da Educação na produção sobre o tema, a expectativa era de que fosse encontrada quantidade maior de material nas outras áreas, ou ao menos que a discrepância entre elas não fosse tão grande neste aspecto. 


\section{Os anais e periódicos acadêmicos}

A ausência de produção sobre o tema ocorre em cinco revistas: Estudos Históricos,
Revista de Administração, Revista de Economia Política, Economia e Sociedade e Novos Estudos Cebrap. Nos outros títulos, a distribuição dos artigos, em números absolutos, é a seguinte:

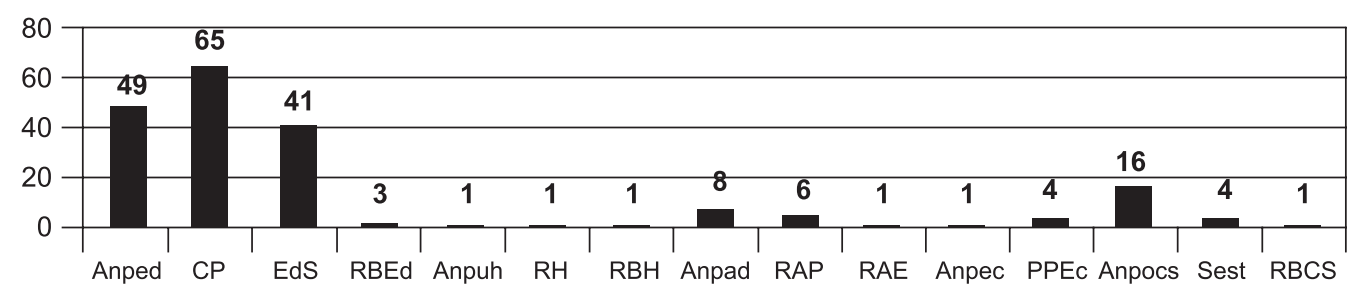

Gráfico 2 - Distribuição dos artigos por publicação

No Gráfico 2 fica novamente evidenciada a predominância da Educação como a grande debatedora do tema analisado no período. Nas demais áreas destacam-se as Ciências Sociais e a Administração como aquelas que também o discutem, embora em escala muito menor.

Na Tabela 1 pode-se observar que, na década de 70, há a menor produção sobre o tema (10\%). Esta quantidade de trabalhos pode ser parcialmente explicada por três fatores principais: 1) somente nove das 20 publicações existiam desde 1971; 2) cinco delas foram criadas no decorrer desta década e seis, nas décadas seguintes; e 3) a relativa dificuldade de localização de registros, programas, anais e textos integrais das reuniões das Associações Nacionais pesquisadas, do início do período.
A década de 80 contempla um aumento na produção sobre o tema, com 31\% dos trabalhos analisados, confirmando a tendência iniciada ao final dos anos 80, que permanece durante os anos 90 (59\%). Esse crescimento contínuo na produção sobre o tema demonstra seu recente reconhecimento como campo de pesquisa.

Outro dado que se pode destacar é a distribuição da produção entre anais (37\%) e revistas (63\%), com disposição temporal diferenciada. Embora na década de 90 esteja a maioria da produção acadêmica selecionada, há uma maior quantidade dessa produção nos anais que nas revistas.

Por outro lado, no total do período, há maior quantidade de publicação em revistas nas áreas de Educação, História e Economia, e, em anais das reuniões das associações, nas de Administração e Economia.

Tabela 1 - Produção acadêmica por área, tipo de publicação e período

\begin{tabular}{|c|c|c|c|c|c|c|c|c|}
\hline Área & $\begin{array}{l}1971- \\
1975\end{array}$ & $\begin{array}{l}1976= \\
1980\end{array}$ & $\begin{array}{l}1981= \\
1985\end{array}$ & $\begin{array}{l}1986- \\
1990\end{array}$ & $\begin{array}{l}1991- \\
1995\end{array}$ & $\begin{array}{l}1996= \\
2000\end{array}$ & $\begin{array}{c}\text { Totais } \\
\text { parciais }\end{array}$ & $\begin{array}{l}\text { Total } \\
\text { geral }\end{array}$ \\
\hline Educação - Anais & 0 & 0 & 1 & 2 & 10 & 36 & 49 & \multirow{2}{*}{158} \\
\hline Educação - Revistas & 0 & 13 & 22 & 30 & 26 & 18 & 109 & \\
\hline História - Anais & 1 & 0 & 0 & 0 & 0 & 0 & 1 & \multirow{2}{*}{3} \\
\hline História - Revistas & 1 & 0 & 0 & 0 & 0 & 1 & 2 & \\
\hline Administração - Anais & 0 & 0 & 1 & 1 & 4 & 2 & 8 & \multirow{2}{*}{15} \\
\hline Administração - Revistas & 2 & 0 & 1 & 1 & 3 & 0 & 7 & \\
\hline Economia - Anais & 0 & 0 & 0 & 0 & 0 & 1 & 1 & \multirow{2}{*}{5} \\
\hline Economia - Revistas & 1 & 2 & 0 & 0 & 0 & 0 & 4 & \\
\hline Ciências Sociais - Anais & 0 & 0 & 0 & 0 & 1 & 14 & 16 & \multirow{2}{*}{21} \\
\hline Ciências Sociais - Revistas & 0 & 0 & 0 & 0 & 1 & 2 & 5 & \\
\hline Total - Anais/década & \multicolumn{2}{|c|}{1} & \multicolumn{2}{|c|}{6} & \multicolumn{2}{|c|}{68} & 75 & \\
\hline Total - Revistas/década & \multicolumn{2}{|c|}{19} & \multicolumn{2}{|c|}{57} & \multicolumn{2}{|c|}{51} & 127 & 202 \\
\hline Total - Produção/década & \multicolumn{2}{|c|}{20} & \multicolumn{2}{|c|}{63} & \multicolumn{2}{|c|}{119} & - & 202 \\
\hline
\end{tabular}




\section{Temas identificados}

Se a pesquisa a respeito da Educação contempla uma multiplicidade de possibilidades temáticas, o mesmo ocorre na produção sobre a relação Estado e Educação. Foram identificados, no decorrer da análise dos artigos, sete grandes temas, a saber: 1) Papel do Estado e Educação (Estado); 2) Função e papel da Educação/escola (Função); 3) Diretrizes e paradigmas educacionais (Diretrizes); 4) Normas e documentos oficiais (Normas);
5) Políticas educacionais: concepções, planos e programas (Concepções); 6) Implementação de políticas educacionais e gestão de sistemas educacionais: (Implementação); e 7) Gestão escolar (Gestão).

Sua distribuição no período é apresentada no Gráfico 3. Ressalte-se que em muitos trabalhos discutiam-se vários aspectos de uma questão, havendo a possibilidade de sua classificação em mais de um tema. Optou-se, nestes casos, por relacioná-lo àquele entendido como seu foco principal.

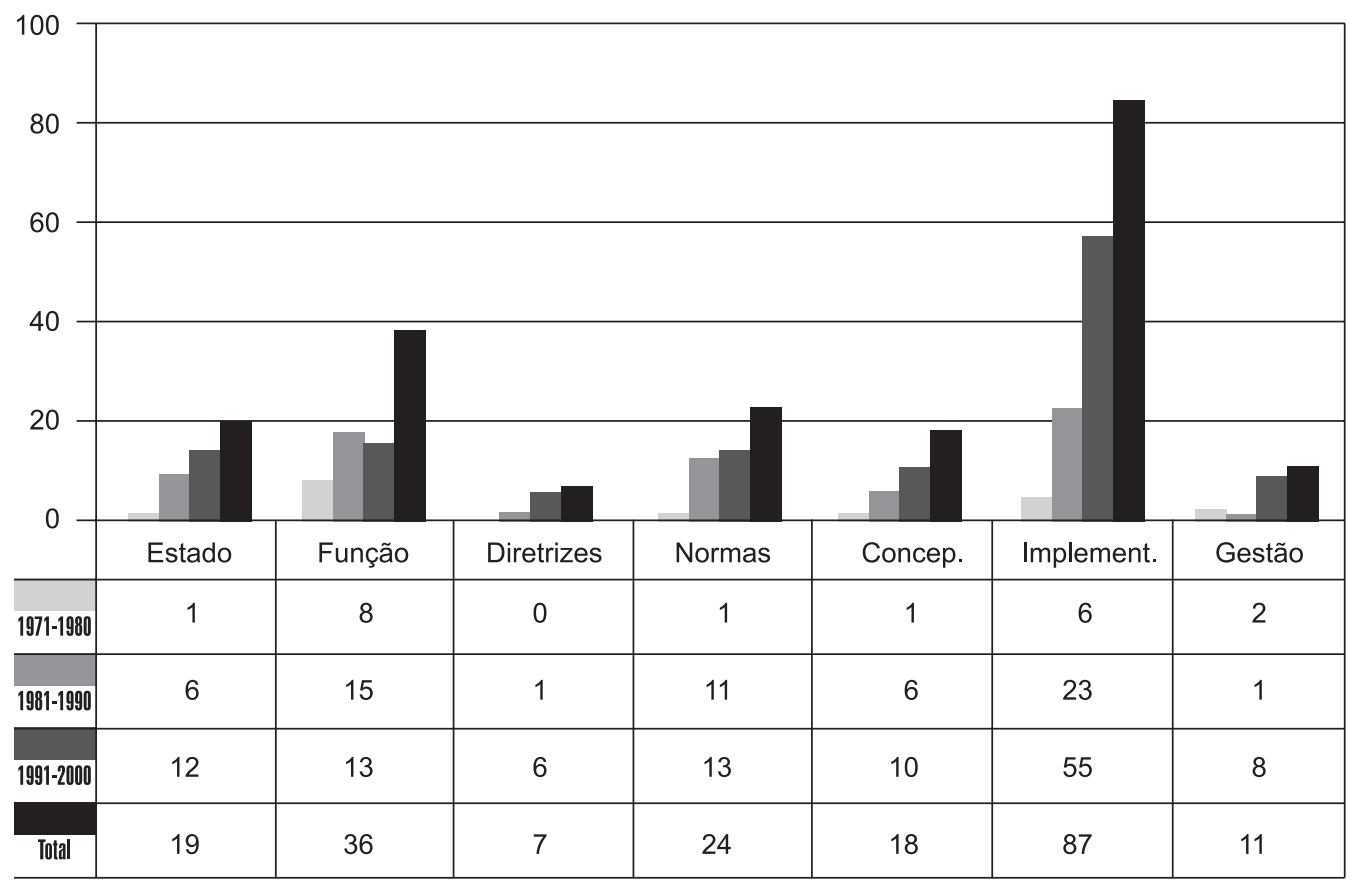

Gráfico 3 - Distribuição dos temas, por década

Nesse gráfico, percebe-se que o tema Implementação é o mais intensamente tratado, totalizando $43 \%$ dos artigos. Discutese nele aspectos predominantemente empíricos de políticas educacionais. Há um grande contraste se comparado a Concepções (9\%), no qual é discutida a elaboração de planos e programas educacionais. Embora tratando da mesma questão, estes temas enfocam faces distintas dela.

Se os temas forem divididos em aqueles voltados para análises de aspectos empíricos da relação Estado e Educação e aqueles que tratam de elementos conceituais e teóricos, pode-se notar a grande ênfase no primeiro grupo, constituído por Estado, Função, Implementação e Gestão, que, juntos, somam $76 \%$ dos trabalhos, enquanto
$24 \%$ seriam do segundo, composto por Diretrizes, Normas e Concepções.

Destaque-se que Normas, o mais representativo do segundo grupo (12\%), na verdade trata de questões-limite entre o empírico e o conceitual, uma vez que nele também é discutida a aplicação das diretrizes legais estabelecidas.

Entre os temas mais práticos a escola é pouco discutida: Gestão, em que se trata mais diretamente deste aspecto, corresponde a apenas $5 \%$ dos trabalhos. Por sua vez, entre os mais teóricos, Diretrizes foi pouco abordado (3,5\%), sendo este o tema menos tratado em toda a produção analisada.

A participação relativa dos temas quanto ao total de trabalhos de cada década e ao total analisado é apresentada na Tabela 2. 
Tabela 2 - Participação relativa dos temas, ${ }^{*}$ por década (\%)

\begin{tabular}{|c|c|c|c|c|}
\hline Tema & Década 70 & Década 80 & Década 90 & $\begin{array}{l}\text { Total do } \\
\text { período }\end{array}$ \\
\hline 1. Papel do Estado e Educação & 5 & 8 & 11 & 9 \\
\hline 2. Função e papel da Educação/escola & 43 & 23 & 15 & 18 \\
\hline 3. Diretrizes e paradigmas educacionais & 0 & 2 & 5 & 4 \\
\hline 4. Normas e documentos oficiais & 5 & 18 & 10 & 12 \\
\hline $\begin{array}{l}\text { 5. Políticas educacionais: concepções, } \\
\text { planos e programas }\end{array}$ & 5 & 10 & 9 & 9 \\
\hline $\begin{array}{l}\text { 6. Implementação de políticas educacionais } \\
\text { e gestão de sistemas educacionais }\end{array}$ & 33 & 37 & 47 & 43 \\
\hline 7. Gestão escolar & 9 & 2 & 7 & 5 \\
\hline Total & 100 & 100 & 100 & 100 \\
\hline
\end{tabular}

* Participação relativa ao total de cada década: década de 70: 20; década de 80: 63; década de 90: 119; e total: 202.

Nesta tabela fica evidenciada a predominância do tema Implementação durante as três décadas e, conseqüentemente, também no total da produção acadêmica, com crescente participação, no período analisado.

Quanto à perspectiva de participação relativa dos temas na produção de cada década, Implementação e Estado são os únicos que apresentam contínuo crescimento. Em Função o movimento é decrescente, e nos demais, variável.

\section{Referências ao Estado}

Os trabalhos selecionados também foram classificados conforme as referências que continham sobre o Estado. Estas menções correspondem aqui às características e críticas, ou seja, ao entendimento dos autores sobre a atuação estatal em relação à questão educacional. Ressalte-se que não se pretendeu, com a classificação proposta, contemplar todas as possibilidades de caracterização do Estado, mas somente as principais ênfases a respeito dele, no material pesquisado.

Da mesma maneira que os temas, as referências ao Estado não foram pré-fixadas, mas identificadas e agrupadas no decorrer da leitura e análise dos artigos. Porém, diferentemente do critério adotado na classificação dos temas - na qual optou-se por fazê-lo a partir da ênfase principal -, nas referências os trabalhos foram vinculados a mais de uma delas, conforme o caso, a fim de se observar as diferentes perspectivas e críticas dos autores à atuação estatal.

No Gráfico 4 observa-se a distribuição dessas referências. Nele estão retratadas as menções feitas ao Estado, nos 202 artigos analisados, mas a distribuição apresentada refere-se a 296 registros, uma vez que em vários trabalhos houve mais de uma.

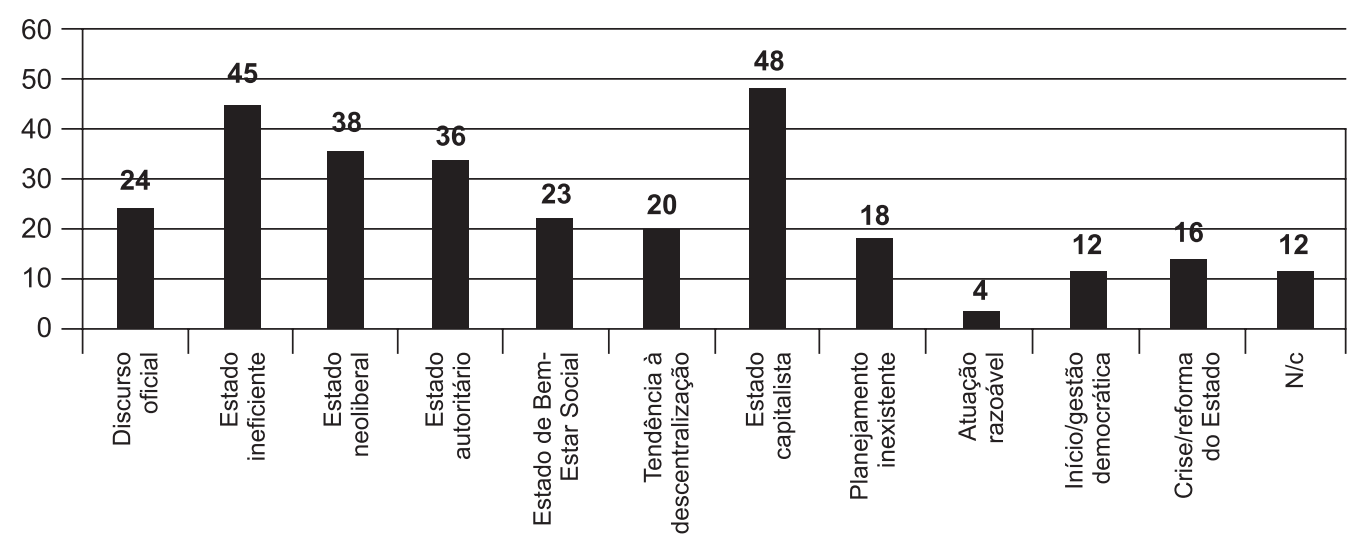

Gráfico 4 - Distribuição da classificação dos artigos - referências ao Estado (296) 
Percebe-se que as principais ênfases são ao Estado capitalista (16\%), à sua ineficiência ou omissão (15\%), ao modelo neoliberal (13\%) e ao seu autoritarismo (12\%). Estas quatro referências, juntas, representam mais da metade das indicações dos artigos.
Uma distribuição delas no decorrer do período pesquisado pode ser útil para verificar quais percepções predominam em cada década. A Tabela 3 traz esta informação.

No período de 1971 a 1980, 40\% dos artigos versaram sobre o Estado capitalista/

Tabela 3 - Distribuição das referências ao Estado, por década

\begin{tabular}{|c|c|c|c|c|}
\hline Referências ao Estado & Década 70 & Década 80 & Década 90 & Total \\
\hline 1. Discurso oficial / legislação x prática & 1 & 1 & 12 & 24 \\
\hline 2. Estado ineficiente / omisso & 3 & 9 & 23 & 45 \\
\hline 3. Estado neoliberal / Estado mínimo & 0 & 5 & 33 & 38 \\
\hline 4. Estado autoritário / centralizador & 4 & 2 & 20 & 36 \\
\hline 5. Estado de Bem-Estar Social & 1 & 0 & 12 & 23 \\
\hline 6. Tendência à descentralização & 0 & 1 & 19 & 20 \\
\hline 7. Estado capitalista / reprodutor da ordem social & 10 & 5 & 13 & 48 \\
\hline 8. Planejamento inexistente / não aplicado/ ineficaz & 2 & 5 & 11 & 18 \\
\hline 9. Atuação do Estado razoável ou positiva & 1 & 0 & 3 & 4 \\
\hline 10. Início / processo de abertura para gestão democrática & 0 & 0 & 12 & 12 \\
\hline 11. Crise e reforma do Estado & 0 & 0 & 16 & 16 \\
\hline 12. Não consta & 2 & 4 & 6 & 12 \\
\hline Totais & 24 & 91 & 180 & 296 \\
\hline
\end{tabular}

reprodutor da ordem social e $16 \%$, sobre sua ineficiência/omissão e seu autoritarismo (mesmo índice em ambos). Nos estudos destes anos há uma grande ênfase crítica ao modelo de Estado, em especial quanto à sua vinculação aos interesses de uma minoria dominante, representada especialmente pelos militares e as correntes políticas mais conservadoras.

Este entendimento permanece, em linhas gerais, na década seguinte, na qual $27 \%$ das menções são ao Estado capitalista, $20 \%$ à sua ineficiência e $13 \%$ a seu autoritarismo e centralização excessivos.

Na década de 1990, há 18\% das referências destacando o Estado neoliberal/mínimo, 13\% tratando da ineficiência e omissão estatal, 11\% referentes ao seu autoritarismo e 10\% indicando a tendência à descentralização.

Percebe-se que na década de 70 a discussão era mais homogênea, ou seja, havia um entendimento claramente predominante. No decorrer das décadas de 80 e 90, as referências ao Estado vão abrangendo outros aspectos da questão, tornando-se mais diversificadas.

Nas referências identificadas, somente duas - Atuação do Estado como razoável ou positiva e Início/processo de abertura para gestão democrática - correspondem a ênfases não totalmente negativas, ou seja, que não abordam apenas problemas do Estado e de sua atuação. Ou seja, na quase totalidade dos artigos analisados, são elaboradas críticas à atuação ou ao modelo de Estado.

A distribuição destas referências nas três décadas analisadas indica os rumos que as críticas foram tomando e quais foram intensificadas no decorrer do período. Por outro lado, elas também podem ser percebidas por meio das expectativas apresentadas nos artigos, o que será visto em seguida.

\section{Expectativas, indicações e sugestões}

Procurou-se aqui identificar as demandas dos autores a respeito da atuação do Estado ante a Educação. A classificação deste elemento nos artigos seguiu o mesmo padrão de elaboração que as referências: foi criada durante a leitura e análise dos trabalhos. 
Nesta classificação também foi utilizado o critério cumulativo, o que resultou na identificação de 397 itens nos 202 artigos, como pode ser observado no Gráfico 5.

Das expectativas presentes nos artigos analisados, destacam-se: gestão participativa $\mathrm{real} /$ mobilização da sociedade (17\%), revisão do papel do ensino e da função da escola (13\%), democratização da educação (11\%), descentralização com critérios democráticos e recursos financeiros e Educação e combate às desigualdades (ambas com 9\%).

A distribuição destas expectativas, indicações e sugestões ao longo das três décadas é apresentada na Tabela 4.

Na década de 70, as principais expectativas são quanto à revisão do papel da
Educação e da escola (20\%), à democratização da Educação (17\%) e ao combate às desigualdades (15\%), ou seja, mais ideais e amplas.

Na década de 1980, as demandas são predominantemente vinculadas à ação do Estado, com uma cobrança mais direta de suas responsabilidades. Destacam-se as expectativas de revisão do papel da Educação e da escola (15\%), de gestão participativa $\mathrm{real} / \mathrm{mobilização} \mathrm{da} \mathrm{sociedade} \mathrm{(12 \% ),} \mathrm{de}$ maior comprometimento do Estado com a Educação (11\%), de redefinição/vinculação orçamentária e prestação de contas (10\%) e de descentralização com critérios democráticos e recursos financeiros (9\%).

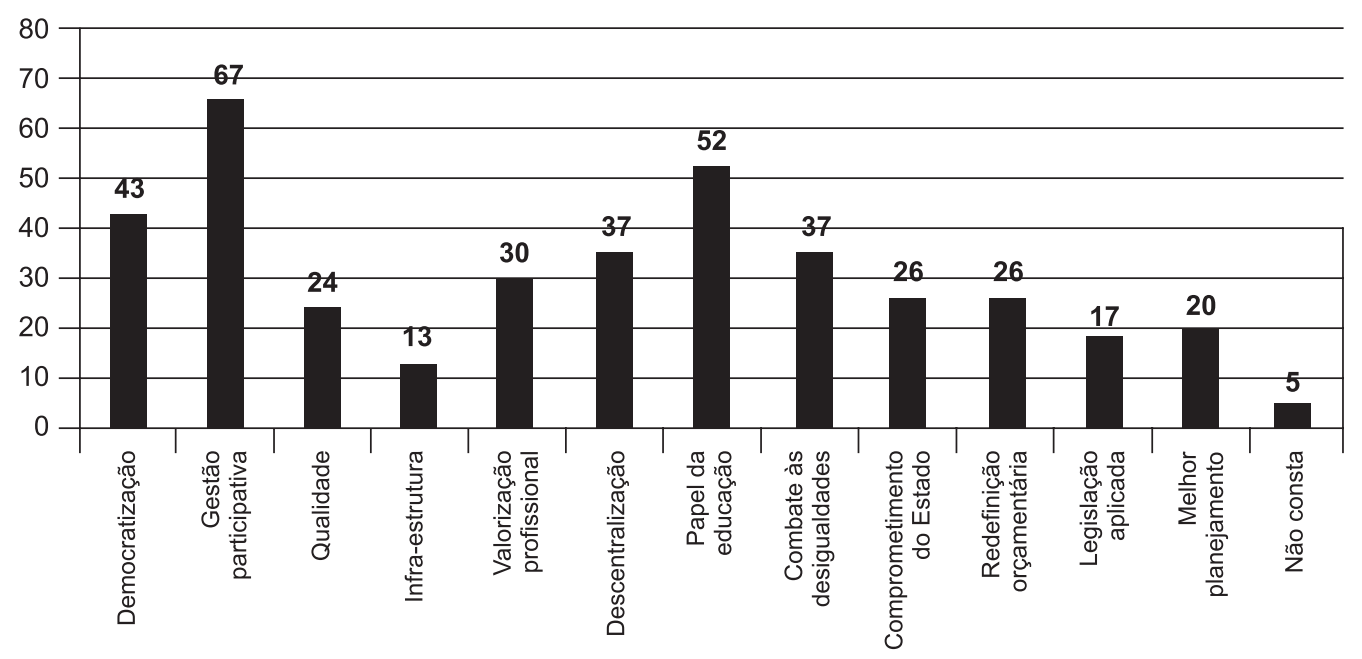

Gráfico 5 - Distribuição da classificação dos artigos - expectativas (397)

Tabela 4 - Distribuição das expectativas, por década

\begin{tabular}{l|c|c|c|}
\hline \multicolumn{1}{|c|}{ Expectativas } & Década & Década & Década \\
\hline & 70 & 80 & 90 \\
\hline
\end{tabular}


Nos anos 90 ocorre uma maior ênfase à gestão participativa real/mobilização da sociedade (21\%), à democratização da Educação (12\%), à revisão do papel da Educação e da escola (11\%), à descentralização com critérios democráticos e recursos financeiros (10\%) e à Educação como caminho para o combate às desigualdades (9\%).

Nota-se que a revisão do papel da Educação está presente nas três décadas como bastante citada, embora sua participação relativa vá diminuindo. A democratização e o combate às desigualdades, destacadas na década de 70, são menos indicadas na década de 80 - quando a maior ênfase é na revisão do papel do ensino e da função da escola, na gestão participativa e no comprometimento do Estado - e retornam como expectativa forte na década de 90.

A demanda pela gestão participativa cresce bastante no decorrer do período, juntamente com a de descentralização sob critérios democráticos e recursos financeiros adequados. Esta discussão parece estar relacionada com as questões que envolvem o Estado neoliberal, como, por exemplo, a adoção do termo gestão, que tem uma conotação que a liga à administração de empresas privadas. Por outro lado, as expectativas quanto ao comprometimento do Estado com a Educação e a redefinição/ vinculação orçamentária e prestação de contas, fortes na década de 1980, são menos citadas na década seguinte.

\section{Contextualizando}

Neste tópico, os dados apresentados quanto aos temas, referências e expectativas são discutidos, considerando-se o contexto histórico do período.

A partir das classificações realizadas quanto às referências ao Estado, observouse a denúncia quanto à ineficácia de sua atuação, bem como aos problemas que ela trazia ou criava e suas conseqüências para a Educação. Nas décadas de 70 e 80, as ênfases ao Estado capitalista e reprodutor da ordem social, à sua ineficiência e omissão e ao seu perfil autoritário e centralizador permeiam a grande maioria dos trabalhos.

Considerando-se o contexto destes anos, estas críticas podem ser situadas nas discussões a respeito do final do regime militar e da transição democrática, que é bastante questionada pela especificidade do caso brasileiro, no qual houve a continuidade, no poder, de políticos vinculados aos militares, ou seja, justamente ligados àqueles que simbolizavam características que se pretendia superar na construção de um país democrático, uma vez que eram entendidos como retrógrados, autoritários, antidemocráticos e ineficientes. As menções feitas ao Estado, então, refletem e discutem este impasse e indignação, como também expectativas e esperanças dos autores.

Nos anos 70, as demandas voltam-se para a revisão do papel do ensino e da função da escola, democratização da educação e combate às desigualdades. Obviamente estão inter-relacionadas, uma vez que se esperava a democratização da escola - entendida neste momento principalmente como acesso e permanência, pois ainda não se colocava com destaque a questão da qualidade - , transformando-a em menos seletiva, que poderia levar à diminuição dos problemas e da desigualdade social do Brasil.

Destaca-se a potencialidade da escola para contribuir para a mudança social almejada, na medida em que seu modelo e objetivos fossem revistos e direcionados para o atendimento de necessidades das amplas camadas populares. Para isso, contribuem as demais demandas quanto aos professores e à gestão participativa.

O Estado manteria o papel de provedor das políticas públicas, mas com uma atuação permeada pela participação popular, que lhe garantiria maior legitimidade, na medida em que voltasse suas ações para o atendimento e acesso da população. Ou seja, embora não abordado diretamente, demanda-se um fortalecimento do Sistema de Proteção Social do País, aliado a um processo de renovação política e de democratização das instituições públicas.

O quadro de recessão econômica, transição política e problemas sociais permeou a década de 80 e levou a situações de grande peso simbólico, enquanto catalizadores de esperanças da população, também presentes nos trabalhos, como as Diretas Já, a eleição de Tancredo Neves e a Assembléia Nacional Constituinte.

As expectativas da população voltavamse, em síntese, para a solução dos problemas econômicos e sociais do País, mais do que dos problemas políticos, aparentemente menos imediatos e percebidos, embora começasse a se desenvolver uma crescente percepção a respeito dessa relação, o que pode ser observado pela mobilização da população nos eventos já citados. 
Desta maneira, as principais menções ao Estado, na produção acadêmica, são bastante parecidas com as do período anterior, com o perfil capitalista em primeiro plano, mas agora com a ineficiência e omissão estatais mais destacadas que seu autoritarismo e centralização. À medida que o regime militar vai perdendo sua força, esta última referência é menos citada, uma vez que era uma das principais oposições feitas a ele, e as críticas ao Estado vão sendo expandidas e complexificadas. Outros aspectos são inseridos na discussão sobre seu papel e relacionados como faces e explicações possíveis para os problemas observados.

Uma dessas críticas, que ganha maior destaque, é a da distância entre discurso oficial e legislação e a prática ou o encaminhamento do Estado a essas questões, o que está relacionado com a sua discutida ineficiência e omissão, que tem uma ênfase mais ideológica, com o entendimento de intencionalidade, na medida em que, no modelo capitalista de Estado então vigente, seria uma das formas de manutenção da ordem social, utilizada pelas classes dominantes. Dessa forma, a ineficiência poderia ser conseqüência dessa omissão e, portanto, também intencional, mesmo que indiretamente.

Esta intencionalidade se manifesta de diversas formas, entre as quais o dizer-se ou garantir-se direitos, simultaneamente à inação do Estado, no sentido de garantilos efetivamente. Relacionada com estas garantias, surge a referência ao Estado de Bem-Estar Social e menções indiretas à crise do Estado.

De certa forma, mesmo que não intencionalmente, pode ser que as discussões, as críticas e os argumentos a respeito da ineficiência e omissão do Estado e de seu Sistema de Proteção Social tenham colaborado ou sido utilizados distorcidamente para justificar, no discurso oficial, a mudança do modelo estatal, para um que primasse por mais eficiência, via racionalização de seus gastos. Obviamente, as críticas aos problemas que os autores observaram e evidenciaram nos trabalhos visavam à organização de um outro perfil de Estado, que não se concretizou.

$\mathrm{Na}$ década de 80 as expectativas do período anterior permanecem, mas com disposição distinta quanto às ênfases. A revisão do papel da Educação e da escola mantém-se como a principal delas, como também o entendimento de seu papel enquanto conscientizadora dos cidadãos. Porém diminui aqui a ênfase em sua possibilidade potencial de transformadora da realidade. Talvez devido às expectativas e frustrações que permearam estes anos, a Educação não é considerada com força suficiente para levar à mudança do panorama político e social, mas sim como uma das condições para que isto ocorra, devendo estar necessariamente acompanhada de outras medidas políticas, econômicas e de garantia efetiva de direitos por parte do Estado.

Tanto que as duas outras expectativas mais presentes nos trabalhos dos anos 80 são de gestão participativa real e mobilização da sociedade civil e de comprometimento do Estado com a Educação. Nesta perspectiva, a primeira está relacionada mais diretamente com o contexto mobilizador, e a segunda, aos caminhos esperados para um outro modelo de Estado, que priorizasse a Educação além do discurso e da legislação, realizando as medidas necessárias para que as demandas da população sejam atendidas, ou seja, em oposição à distância citada. Esta expectativa está bastante relacionada com a segunda metade da década, no âmbito de debates e de demandas que envolveram a elaboração da Constituição Federal, promulgada em 1988.

Parte desta discussão tratou de caminhos necessários para essa efetivação dos direitos, sendo que a redefinição e vinculação orçamentárias, com prestação de contas, e a descentralização, com critérios democráticos e recursos financeiros adequados, são expectativas bastante citadas nesse período. Ambas indicam demandas mais concretas e específicas, com relação à atuação esperada do Estado no campo educacional, e são acompanhadas de perto pelo destaque à necessidade de legislação que se efetive na prática.

Parece que esta preocupação ficou mais clara principalmente após a promulgação da nova Constituição, que, se trouxe avanços em relação aos direitos da população, não contemplou demandas no sentido de estabelecer de que forma estes direitos seriam garantidos na prática.

Neste sentido, reduz-se a perspectiva do papel do Estado como efetivo provedor nas políticas públicas, na medida em que se evidencia cada vez mais sua priorização a questões econômicas, ao invés das sociais. A gestão participativa da sociedade civil, por meio de mecanismos que devem ser criados para permitir que isto ocorra, é que deve, neste caso, ser fortalecida e integrada 
no sistema decisório estatal. Esta discussão também estará presente no período seguinte.

Na década de 90 destacam-se a presidência de Fernando Collor de Mello, com a discussão, no País, a respeito da relação entre a corrupção e o poder, a de Itamar Franco, com o Plano Real, que finalmente permite o controle inflacionário, e a eleição de Fernando Henrique Cardoso, em cujo governo é trazida à discussão a questão da crise e reforma do Estado. Tem início uma fase de privatização de serviços, antes prestados pelo Estado, sob a principal justificativa de busca de maior eficiência e de benefícios para a população.

A credibilidade e o apoio popular ao governo são menores ao final de 1998, mas ainda razoáveis, e FHC é reeleito. Porém, neste segundo mandato, problemas econômicos internos e externos ao País levam a uma estagnação de seu crescimento, com aumento do desemprego, e a uma imobilização do governo sobre as reformas pretendidas. O grande descontentamento da população a respeito desta situação foi um dos fatores que contribuíram para a eleição de Luiz Inácio Lula da Silva para presidente da República nas eleições de 2002.

Na produção acadêmica da década de 90, as referências ao Estado são mais distintas em relação às das décadas anteriores. A principal menção é ao Estado neoliberal/mínimo. Da mesma forma que no perfil capitalista, mais indicado nos anos 70 e 80, os questionamentos a este modelo ocorrem como denúncia dos problemas que ele traz por princípio.

Por sua vez, a ineficiência e omissão estatais permanecem como a segunda característica mais citada, porém agora com outra ênfase. A ineficiência está, neste momento, mais relacionada com a discussão da crise do Estado e do Sistema de Proteção Social, e a omissão, se permanece no sentido da intencionalidade, passa também a ser discutida enquanto desresponsabilização do Estado ante as demandas sociais da população, atitude implícita no modelo neoliberal então criticado.

É interessante que neste momento o perfil autoritário e centralizador do Estado permaneça ainda destacado, simultaneamente à indicação da tendência à descentralização. Este aparente paradoxo deve-se ao entendimento de que esta descentralização se refere às responsabilidades do Estado entre os diferentes níveis de governo, embora o governo federal mantenha centralizado o controle e a avaliação dos resultados.
Conforme destacado, nessa década a crise e a reforma do Estado são bastante abordadas, assim como o neoliberalismo, a ineficiência, a desresponsabilização, a centralização e a descentralização, uma vez que estão inter-relacionadas. Outras menções são a oposição entre discurso oficial, legislação e prática e o início do processo de abertura para a gestão democrática - ambas discutindo os problemas de implementação das garantias constitucionais, como os mecanismos que permitiriam essa desejada gestão, também preconizada pela nova LDB de 1996.

A grande expectativa dos anos 90 é de gestão participativa e mobilização da sociedade civil para a garantia e conquista das demandas e direitos da população, ou seja, também como forma de questionamento dos rumos políticos e econômicos do País, em especial quanto ao papel do Estado.

A democratização da Educação tem uma outra ênfase: antes referindo-se ao acesso e à permanência, agora é discutida quanto à gestão escolar, à participação da comunidade e da sociedade civil no estabelecimento e na defesa de seus rumos, além da questão da qualidade do ensino, que neste momento é evidenciada.

A expectativa por democratização também está relacionada com as de revisão do papel do ensino e da função da escola, com ênfase na gestão democrática; de combate às desigualdades, que é fortalecido nesta década, entendido como um caminho necessário e que deve ser permeado pela discussão, interesse e participação política da população na conquista de seus direitos e de maior justiça social; de descentralização com critérios democráticos e recursos financeiros, relacionada com a gestão democrática quanto à participação da comunidades local sobre os rumos e investimentos na Educação nos municípios, por exemplo; e de valorização e revisão do papel dos profissionais da Educação, inseridos nesta discussão sobre seu papel neste processo de formação e conscientização, além de mencionarem a questão salarial e a capacitação profissional.

Os recursos financeiros são abordados na expectativa do tipo de descentralização almejado: sua distribuição, garantia (vinculação) e uso, em especial tratando-se das diretrizes constitucionais a este respeito e do Fundef. A revisão, vinculação orçamentária e prestação de contas por parte do Estado complementam este quadro de demandas, embora com menor peso que na 
década anterior, possivelmente devido ao fato de a legislação que definiria esta questão já estar vigente (Constituição) ou ter sido aprovada na segunda metade da década (LDB e Fundef).

\section{Considerações finais}

A fim de evitar a redundância a temas já anteriormente destacados e para melhor pontuar algumas constatações, são enumeradas abaixo observações consideradas importantes no âmbito deste trabalho:

1) Contrariando uma expectativa inicial, não foi encontrada, nas áreas pesquisadas - com exceção da Educação -, produção quantitativamente significativa a respeito do tema.

2) A compreensão sobre a função e o papel do Estado em relação à Educação pôde ser observada, bem como os rumos que foi tomando no decorrer dos trinta anos pesquisados. Neste sentido, a década de 1970 caracterizase como de denúncia, principalmente da atuação do Estado sob diretrizes capitalistas, seguida de longe pela referência a seu perfil autoritário e centralizador. Os anos 80, além de intermediários no período delimitado, também acabam por apresentar esta característica na produção analisada. Há predominância da referência à ineficiência e omissão do Estado seguida por várias outras, como ao capitalismo, ao neoliberalismo e aos problemas de planejamento. Finalmente, na década de 1990 há uma maior concentração no modelo neoliberal, além de outros elementos que a ele estão relacionados, como sua ineficiência e omissão (agora entendidas como desresponsabilização), centralização de controle e poder e descentralização de responsabilidades, e seu processo de crise e reforma.

3) As expectativas presentes nos trabalhos também vão mudando, ao longo do tempo. Do destaque à democratização da Educação nos anos 70, entendida como acesso e permanência, nos anos seguintes as demandas voltam-se para a revisão do papel da escola e para a sua gestão participativa. Esta última passa a ser a principal necessidade indicada nos trabalhos da década de 1990, além da democratização - agora compreendida principalmente como busca por qualidade e maior participação da sociedade civil -, da revisão da função da escola e de critérios mais democráticos para o processo de descentralização que se desenvolve.

4) Uma suposição confirmada foi a de que o contexto que envolve as décadas acabou por dar o tom dos discursos presentes na produção acadêmica. Acredita-se aqui que o resgate histórico desenvolvido sobre o período e os trabalhos selecionados pôde contribuir para esta percepção e para a compreensão mais ampla das relações existentes entre a história e a construção das interpretações sobre ela, no que diz respeito ao tema abordado.

5) Em cada uma das décadas analisadas, e mais notadamente nos anos 80 e 90, observou-se um curto período entre as ocorrências políticas e econômicas e sua discussão nas publicações, relacionando-as à Educação. Porém, este intervalo é muito mais curto do que se imaginava ao início da pesquisa. Desta forma, uma das características que se pode indicar sobre a produção é sua atualidade.

Se esta atualidade dos temas gera a positiva contribuição a respeito do debate sobre os problemas e rumos da Educação, por outro lado, pode significar também embaçamento na visão dos autores a respeito deles, sem o distanciamento que permitisse maior objetividade no tratamento do tema. Em que pesem a complexidade da questão educacional e as especificidades da pesquisa neste campo, acredita-se aqui que este é um elemento ainda indispensável na produção de conhecimento científico, embora com as peculiaridades que abrangem a área. ${ }^{3}$

6) Um outro elemento identificado é a tendência à repetição de idéias, ao mesmo tempo em que há uma grande fragmentação na produção quanto a temas e perspectivas. Assim, alguns problemas são levantados, discutidos e abordados repetida e incansavelmente, com poucas diferenças ou lentos avanços em seu entendimento. 
Possivelmente uma organização e coordenação da área quanto aos conhecimentos e estudos nela desenvolvidos poderia contribuir para minimizar alguns dos problemas e lacunas identificados.
Este esforço já vem sendo desenvolvido, ao menos nos anos mais recentes, por Associações Nacionais da área de Educação, como a Anped e a Anpae, mas precisa ser intensificado.

\section{Referências bibliográficas}

BARDIN, Laurence. Análise de conteúdo. Lisboa: Edições 70, 1977.

BOURDIEU, Pierre. Lições da aula. São Paulo: Ática, 1988.

BRAUDEL, Fernand. Escritos sobre a história. São Paulo: Perspectiva, 1978.

BURKE, Peter. Abertura: a nova história, seu passado e seu futuro. In: A escrita da história: novas perspectivas. São Paulo: EdUnesp, 1992. p. 8-37. (Biblioteca Básica)

CARDOSO, Ciro F; VAINFAS, Ronaldo. História e análise de textos. In: Domínios da história: ensaios de teoria e metodologia. Rio de Janeiro: Campus, 1 997. p. 375-399.

CHARTIER, Roger. A história cultural: entre práticas e representações. Lisboa: Difel, 1988.

DRAIBE, Sônia M. Repensando a política social: dos anos 80 ao início dos 90. In: SOLA, L.; PAULANI, L. M. (Org.). Lições da década de 80. São Paulo: Edusp; Genebra: UNRISD, 1995. p. 201-221.

FERREIRA, Norma S. A. As pesquisas denominadas "estado da arte". Educação e Sociedade, Campinas, n. 79, p. 257-272, ago. 2002.

GONÇALVES, Nadia G. Educação: as falas dos sujeitos sociais. São Paulo: Martins Fontes, 2003.

LAMOUNIER, Bolívar. O que preocupa é o tamanho do desafio. Brasil em Exame 1997, São Paulo, v. 20, n. 645, p. 40-42, 1997.

PROST, Antoine. As palavras. In: RÉMOND, René (Org.). Por uma história política. Rio de Janeiro: Ed. UFRJ, 1996. p. 295-330.

SIRINELLI, Jean-François. Os intelectuais. In: RÉMOND, René (Org.). Por uma história política. Rio de Janeiro: Ed. UFRJ, 1996. p. 231-270.

VEIGA NETO, Alfredo J. A ciência em Kuhn e a sociologia de Bourdieu: implicações para a análise da educação científica. Educação e Realidade, Porto Alegre, v. 17, n. 1, p. 93-107, jan./jun. 1992.

Nadia Gaiofatto Gonçalves, doutora em Educação pela Universidade de São Paulo (USP), é professora adjunta do Departamento de Teoria e Prática de Ensino da Universidade Federal do Paraná (UFPR), atuando na disciplina de Metodologia da Pesquisa Educacional, e com pesquisa na área de História da Educação.

nadia_ggoncalves@ufpr.br 


\section{Abstract The relation between State and Education: an analysis of the Brazilian academic production (1971-2000)}

This article presents the results of the research about how the topic State and Education was dealt with in the Brazilian academic production between 1971 and 2000. We have researched five Proceedings of Post-Graduation and Research National Associations and fifteen journals in the areas of Economy, Administration, History, Social Sciences and Education, focusing on four titles in each one of them, considering the total production of the period. We tried to understand the perspectives of the areas which concerns criticism, expectations, understandings regarding the role of the State in Education. We have considered the historical context of the decades in which those works were produced, highlighting their contributions and limitations.

Keywords: State; primary education; educational policies; academic production; historical context and education.

Recebido em 8 de setembro de 2004.

Aprovado em 26 de agosto de 2005. 